\title{
Stabilisation of diabetic retinopathy following simultaneous pancreas and kidney transplant
}

\author{
I A Pearce, B Ilango, R A Sells, D Wong
}

\begin{abstract}
Backgroundlaims-Simultaneous pancreas and kidney transplantation (SPK) has become an important option in selected IDDM patients with end stage renal disease (ESRD). Successful SPK transplants are associated with long term normoglycaemic control and improved quality of life. However, debate still continues on the benefit to patients in terms of stabilisation or amelioration of diabetic retinopathy. The progression of diabetic retinopathy (DR) in a cohort of 20 SPK transplant patients is reported.

Methods-All patients were reviewed postoperatively with corrected visual acuity, slit lamp examination, and fundal biomicroscopy. Preoperative data were collected retrospectively and DR was considered unstable if there had been a drop in Snellen acuity greater than three lines or a need for laser photocoagulation or vitrectomy in the 2 years preoperatively.

Results-20 patients who received SPK transplants between March 1983 and April 1994 were reviewed (mean age 35.1 years; mean duration of IDDM $=\mathbf{2 4 . 6}$ years) .17 patients still had functioning grafts at a mean follow up of 5.1 years. Nine of these patients had unstable DR before transplantation. Of these, $89 \%(8 / 9)$ had stabilised DR following transplantation with only a single case requiring laser photocoagulation. Of the eight patients that had stable DR before transplantation all had stable DR following transplantation. $41 \%$ of cases (7/17) required cataract surgery during the follow up period.

Conclusions-Advanced diabetic retinopathy is present in a high proportion of cases managed with SPK transplant as a consequence of the duration of IDDM and the presence of ESRD. More than $90 \%$ of cases have stable DR following transplant. (Br F Ophthalmol 2000;84:736-740)
\end{abstract}

Royal Liverpool University Hospital, Liverpool L7 8XP

I A Pearce

B Ilango

D Wong

Transplant Unit R A Sells

Correspondence to: Mr D Wong, St Paul's Eye Unit, Royal Liverpool University Hospital, Liverpool L7 8XP

shdwong@msn.com

Accepted for publication 8 February 2000 tions Trial (DCCT) reported that tight metabolic glucose control using intensive exogenous insulin regimens could have a beneficial effect on both the development and progression of retinopathy associated with insulin dependent diabetes mellitus (IDDM). ${ }^{1}$ However, these positive findings were accompanied by a significant increase in the risk of severe hypoglycaemia and in up to $22 \%$ of cases an initial transient worsening of the diabetic retinopathy in the first year.
An alternative approach to tight metabolic control has been pancreas transplantation.

The first pancreas transplant was performed in Minnesota in $1966 .{ }^{2}$ Since then approximately 10000 transplants have been performed worldwide with just over 100 in the $\mathrm{UK}^{3}$

Most recipients of pancreas transplants have been diabetics with end stage renal disease requiring kidney transplant who are thus obliged to receive long term immunosuppression in any case..$^{4-7}$ Thus, over $90 \%$ of pancreas transplants have been simultaneous pancreas and kidney (SPK) transplants. Over the past three decades surgical success has improved with a present patient survival rate of $90 \%$, and $80 \%$ of recipients being insulin and dialysis free. $^{3}$

Several studies from the United States and Europe have reported conflicting results of the affect of pancreas transplantation on diabetic retinopathy. Some studies have reported isolated cases of accelerated deterioration of the retinopathy particularly within the first year. ${ }^{89}$ Other studies have reported regression or stabilisation of the retinopathy status in up to $90 \%$ of cases. ${ }^{9-14}$ But most studies have shown there to be no significant effect on the status of retinopathy when compared with control groups..$^{815-19}$

The aim of our present study was to investigate the effect of SPK transplant on diabetic retinopathy in our own cohort of recipients.

\section{Methods}

CASES

We reviewed all cases of SPK transplants performed at the transplant unit of the Royal Liverpool University Hospital between March 1983 and April 1994. Pretransplant data such as duration of IDDM, history and severity of diabetic retinopathy, previous laser or vitreous surgery were collected retrospectively from case notes. All the cases had been reviewed by an ophthalmologist within 2 years of transplantation. Twenty surviving cases were reviewed post-transplantation with corrected Snellen acuity, slit lamp examination, and dilated fundal biomicroscopy by a single ophthalmologist (IAP).
PATIENT SELECTION, TRANSPLANT SURGERY, AND IMMUNOSUPPRESSION

Between March 1983 and January 1985, insulin dependent diabetics in chronic renal failure were accepted for SPK transplants without objective cardiovascular review. After these dates all potential SPK recipients underwent objective cardiovascular evaluation including 
Table 1 Characteristics of patients with functioning SPK transplants

\begin{tabular}{|c|c|c|c|c|c|c|c|c|c|c|c|c|c|c|}
\hline \multirow{2}{*}{$\begin{array}{l}\text { Patient } \\
\text { No }\end{array}$} & \multirow[b]{2}{*}{ Sex } & \multirow{2}{*}{$\begin{array}{l}\text { Age at } \\
\text { transplant } \\
\text { (years) }\end{array}$} & \multirow{2}{*}{$\begin{array}{l}\text { Duration of } \\
\text { IDDM } \\
\text { (years) }\end{array}$} & \multirow{2}{*}{$\begin{array}{l}\text { Follow up } \\
\text { (years) }\end{array}$} & \multicolumn{2}{|c|}{ Pretransplant VA } & \multicolumn{2}{|c|}{ Post-transplant VA } & \multicolumn{2}{|c|}{ Pretransplant PRP } & \multicolumn{2}{|c|}{$\begin{array}{l}\text { Pretransplant macular } \\
\text { laser }\end{array}$} & \multicolumn{2}{|c|}{$\begin{array}{l}\text { Pretransplant } \\
\text { vitrectomy }\end{array}$} \\
\hline & & & & & $R E$ & $L E$ & $R E$ & $L E$ & $R E$ & $L E$ & $R E$ & $L E$ & $R E$ & $L E$ \\
\hline 1 & M & 42 & 17 & 8.25 & $6 / 6$ & $6 / 6$ & $6 / 6$ & $6 / 6$ & No & No & No & No & No & No \\
\hline 2 & $\mathrm{~F}$ & 37 & 30 & 10 & $6 / 6$ & $6 / 6$ & $6 / 6$ & $6 / 6$ & No & No & No & No & No & No \\
\hline 3 & $\mathrm{~F}$ & 52 & 40 & 1 & $6 / 6$ & $6 / 6$ & $6 / 9$ & $6 / 9$ & No & No & No & No & No & No \\
\hline 4 & M & 32 & 20 & 1.5 & $6 / 6$ & $6 / 9$ & $6 / 6$ & $6 / 9$ & No & No & No & Yes & No & No \\
\hline 5 & $\mathrm{~F}$ & 32 & 12 & 5.25 & $6 / 12$ & $\mathrm{AE}$ & $6 / 9$ & $\mathrm{AE}$ & Yes & $\mathrm{AE}$ & No & $\mathrm{AE}$ & Yes & $\mathrm{AE}$ \\
\hline 6 & M & 37 & 35 & 6.5 & HM & NPL & PL & NPL & Yes & Yes & Yes & Yes & No & Yes \\
\hline 7 & $\mathrm{~F}$ & 42 & 35 & 4 & $6 / 24$ & $6 / 36$ & $6 / 18$ & $6 / 36$ & Yes & Yes & No & No & No & No \\
\hline 8 & M & 36 & 25 & 4.25 & $6 / 18$ & $6 / 60$ & $6 / 18$ & $6 / 60$ & Yes & Yes & No & Yes & No & Yes \\
\hline 9 & $\mathrm{~F}$ & 45 & 20 & 1 & $6 / 18$ & $6 / 36$ & $6 / 12$ & $6 / 24$ & Yes & Yes & Yes & No & No & No \\
\hline 10 & $\mathrm{~F}$ & 30 & 23 & 1 & $6 / 6$ & $\mathrm{CF}$ & $6 / 6$ & PL & Yes & Yes & No & No & No & No \\
\hline 11 & $M$ & 27 & 23 & 9 & NPL & $6 / 12$ & NPL & $6 / 9$ & Yes & Yes & No & No & Yes & No \\
\hline 12 & M & 25 & 23 & 3.5 & $6 / 12$ & $6 / 60$ & $6 / 12$ & $6 / 36$ & Yes & Yes & No & No & No & No \\
\hline 13 & $\mathrm{~F}$ & 29 & 20 & 2 & $6 / 9$ & $6 / 60$ & $6 / 9$ & CF & Yes & Yes & No & No & No & No \\
\hline 14 & $\mathrm{~F}$ & 30 & 19 & 3.25 & $6 / 24$ & NPL & $6 / 24$ & NPL & Yes & Yes & No & No & No & No \\
\hline 15 & M & 34 & 30 & 7.5 & $6 / 12$ & $6 / 9$ & $6 / 12$ & $6 / 6$ & Yes & Yes & No & No & No & No \\
\hline 16 & M & 41 & 25 & 7.5 & $6 / 9$ & CF & $6 / 9$ & HM & Yes & Yes & No & No & No & No \\
\hline 17 & $\mathrm{~F}$ & 34 & 24 & 10.25 & $6 / 12$ & $6 / 9$ & $6 / 12$ & $6 / 9$ & Yes & Yes & No & No & No & No \\
\hline
\end{tabular}

SPK = simultaneous pancreas and kidney transplant, $\mathrm{RE}=$ right eye, $\mathrm{LE}=$ left eye, $\mathrm{IDDM}=$ insulin dependent diabetes mellitus, $\mathrm{PRP}=$ panretinal photocoagulation, $\mathrm{VA}=$ Snellen visual acuity, $\mathrm{AE}=$ artificial eye, $\mathrm{HM}=$ hand movements, $\mathrm{CF}=$ count fingers, $\mathrm{PL}=$ perception of light, $\mathrm{NPL}=$ no perception of light.

stress ECG, stress nuclear ventriculography, and were excluded if they were currently smoking, over the age of 50, or had significant irreversible ventricular ischaemia. ${ }^{20}$

All the cases included in this study had end stage renal failure secondary to diabetic nephropathy.

Segmental pancreatic allografts were placed in the left iliac fossa and the arteriovenous supply of the graft anastomosed with the regional mesenteric vascular tree. The exocrine drainage of the pancreas was into the bladder or jejunum. Cadaveric kidney transplants from the same donor were placed in the right iliac fossa in the conventional manner.

Immunosuppression consisted of "first line" cyclosporin A monotherapy with the addition of azathioprine and/or prednisolone maintenance in $60 \%$ of patients. The aggregate HLA $\mathrm{A}, \mathrm{B}$, and DR antigen mismatches for the whole group was 1:1.1:0.9. Rejection of pancreas or kidney was treated with three pulse doses of intravenous methyl prednisolone (500 $\mathrm{mg}$ ) followed by oral prednisolone supplementation.

\section{PRETRANSPLANT RETINOPATHY STATUS}

Retinopathy was defined as unstable if in the 2 years before transplant there had been a drop in visual acuity of three Snellen lines or more, an episode of vitreous haemorrhage, or if the patient had required either laser photocoagulation or vitrectomy.

As the pretransplant data were collected retrospectively from the case notes it was not possible to give a valid estimate of the grade of retinopathy. In only a very limited number of cases were either pretransplant retinal photographs or fluorescein angiograms available within 2 years of the transplant.

OUTCOME MEASURES

The particular outcome measures we were interested in were:

- Patient survival

- Graft survival

- Ophthalmic complications of transplant surgery or immunosuppression

- Post-transplant retinopathy status.
Progression of retinopathy status was defined as any post-transplantation requirement for laser photocoagulation or vitrectomy.

Stabilisation of retinopathy status was defined as the absence of any requirement for laser photocoagulation or vitrectomy.

Regression of retinopathy status posttransplantation was defined as an improvement in visual acuity of two Snellen lines or more not attributed to clearing of vitreous haemorrhage or cataract surgery.

\section{Results}

PATIENT CHARACTERISTICS

A total of 34 patients received SPK transplants between March 1983 and April 1994. Twenty four patients still survive. Complete pretransplant data and post-transplant review were available for 20 surviving patients (39 eyes). One of these patients had a phthisical eye enucleated 6 years pretransplant. Two of the patients had early rejection of the grafts and proceeded to successful repeat SPK transplantation.

Of the group that we have complete data on, 17 patients (33 eyes) still have both kidney and pancreas grafts functioning and are insulin and dialysis free. The characteristics of this group are presented in Table 1.

The mean age at transplantation of the patients presented in Table 1 is 35.6 years (range 25-52). The mean duration of IDDM before transplantation was 24.8 years (range 12-40). Of the 33 eyes presented in Table 1 , $76 \%$ (25 eyes) had received laser panretinal photocoagulation at some stage before transplantation. Of this same group 15\% (five eyes) had received macular laser and $12 \%$ (four eyes) had vitrectomy performed at some stage before transplantation. There were four cases (eight eyes) which had only mild background DR before transplantation (Table 1: patient Nos 1, $2,3$, and 4$)$. None of these cases required any laser PRP before transplantation. One of these cases had received focal macular laser to one eye before transplantation. The mean posttransplantation follow up is 5.1 years (range 1-10). 
Table 2 Pre-and post-transplantation metabolic/physiological indices

\begin{tabular}{lll}
\hline & Pre-transplant & Post-transplant \\
\hline $\mathrm{HbA}_{1 \mathrm{c}}(\%)$ & 10.6 & 6.4 \\
Serum creatinine $(\mu \mathrm{mol} / \mathrm{l})$ & 885.1 & 248.5 \\
Systolic blood pressure $(\mathrm{mm} \mathrm{Hg})$ & 156 & 148 \\
$\quad$ Mean & $100-190$ & $120-180$ \\
$\quad$ Range & 82 & 88 \\
Diastolic blood pressure $(\mathrm{mm} \mathrm{Hg})$ & $70-100$ & $80-110$ \\
$\quad$ Mean & & \\
$\quad$ Range & & \\
\hline
\end{tabular}

Table 3 Retinopathy status following SPK transplant

\begin{tabular}{llll}
\hline & \multicolumn{2}{l}{ Post-transplant retinopathy status } \\
\cline { 2 - 4 } Pretransplant retinopathy status & Stabilisation \% (n) & Progression \% (n) & Regression \% (n) \\
\hline Successful, SPK transplants & & & \\
$\quad$ Unstable eyes & $94(16 / 17)$ & $6(1 / 17)$ & $0(0 / 17)$ \\
$\quad \begin{array}{l}\text { Stable eyes } \\
\text { Unsuccessful, SPK transplants } \\
\quad \text { Unstable eyes }\end{array}$ & $100(16 / 16)$ & $0(0 / 16)$ & $0(0 / 16)$ \\
$\quad$ Stable eyes & $50(2 / 4)$ & $50(2 / 4)$ & $0(0 / 4)$ \\
& $100(2 / 2)$ & $0(0 / 4)$ & $0(0 / 4)$ \\
\hline
\end{tabular}

Of the group that we have complete data on, three patients (six eyes) have suffered rejection episodes resulting in graft failure (mean age when transplanted $=36$ years; mean length of IDDM $=23$ years)

PATIENT SURVIVAL

Patient survival for SPK transplants over this period was $71 \%(24 / 34)$.

GRAFT SURVIVAL

Overall graft survival in the surviving patients was $75 \%(18 / 24)$. Two patients have received repeat SPK transplants and still have functioning grafts. A further four patients have suffered irreversible rejection episodes and are awaiting repeat transplantation.

The metabolic indices of glycosylated haemoglobin $\left(\mathrm{HbA}_{1 \mathrm{c}}\right)$ and serum creatinine level were significantly improved in patients with successful SPK transplants (Table 2).

OPHTHALMIC COMPLICATIONS

Ten eyes developed cataracts which were not recorded pretransplantation. A total of $41 \%$ (7/17) of successful SPK transplant recipients have proceeded to cataract surgery. Each of these patients was receiving systemic steroids for long term immunosuppression.

Three eyes of two successful SPK transplant recipients developed poor intraocular pressure (IOP) control following transplant surgery (Table 1: patient Nos 6 and 11). Before transplantation patient No 6 had bilateral persistent vitreous haemorrhages but no evidence of raised IOP. Following transplantation this patient developed raised IOP in both eyes with no evidence of angle neovascularisation or ghost cell glaucoma. One eye was subsequently managed with cyclocryotherapy while the other blind eye was comfortable with topical control. Patient No 11 had a previous history of raised IOP as a result angle neovascularisation. This had become stabilised before transplantation but then had again become difficult to control post-transplantation. This eye was subsequently managed with medical therapy. There was no evidence of either angle neovascularisation or retinal neovascular proliferation post-transplantation. Both these patients were receiving long term systemic steroids.

There were no cases of optic neuropathy or cytomegalovirus retinitis.

\section{POST-TRANSPLANT RETINOPATHY STATUS}

Successful SPK transplants

In the group of patients with both grafts still functioning there were 17 eyes that had unstable diabetic retinopathy in the 2 years before transplantation and 16 eyes with stable retinopathy.

Of the 17 eyes with unstable retinopathy pretransplantation 16 eyes (94\%) had stabilisation of the retinopathy following SPK transplant surgery (Table 3). Only one eye had post-transplantation progression of retinopathy. This was from one of the earliest recipients who originally was transplanted in March 1984 (Table 1: patient No 17). She had suffered unstable retinopathy in both eyes before transplantation requiring panretinal photocoagulation (PRP). Within the first 12 months following transplantation she had problems with new vessel formation in her right eye necessitating PRP. Since then she has required no further treatment in either eye and at review over a decade later she is still insulin and dialysis free with acuities of 6/9 and 6/12.

Of the 16 eyes with stable retinopathy pretransplantation none had posttransplantation progression of retinopathy. There were no cases of regression of diabetic retinopathy.

\section{Failed SPK transplants}

In the group of three patients with failed, nonfunctioning SPK transplants there were four eyes that had unstable diabetic retinopathy in the 2 years before transplantation and two eyes with stable retinopathy.

Of the four eyes with unstable retinopathy pretransplantation two eyes $(50 \%)$ had stabilisation of the retinopathy following the initial SPK transplant surgery (Table 3). A further two eyes $(50 \%)$ still had progression of their retinopathy.

Of the two eyes with stable retinopathy pretransplantation none had post-transplantation progression of retinopathy. There were no cases of regression of diabetic retinopathy.

\section{Discussion}

Simultaneous pancreas and kidney transplants have become a viable management option for particular cases of insulin dependent diabetes and end stage renal failure..$^{4-7}$ With improved surgical techniques and immunosuppressive regimens our patient and graft survival rates have been high and comparable with other centres. ${ }^{3}$

Although there are obvious advantages in terms of improved quality of life by being insulin and dialysis free, ${ }^{21-24}$ the effect on established diabetic complications has been questioned. In particular, several studies have given conflicting conclusions of the possible outcomes of SPK transplantation on the course of diabetic retinopathy - that is, improvement, stabilisation, no effect, or deterioration. 
In a study of 25 SPK recipients by Ulbig et al, an improvement in post-transplant visual acuity was found in $32 \%$ of eyes and an improvement in the frequency/severity of vitreous haemorrhages in $46 \%$ of eyes. ${ }^{10}$ Other studies have reported improvements in acuity and retinopathy status but only in approximately $10 \%$ of recipient eyes. ${ }^{911-13}$ Several studies have reported stabilisation of retinopathy in up to $75 \%$ of successful SPK transplant recipients. ${ }^{9} 101314$ In contrast, a number of prospective studies have reported that metabolic normalisation of glycaemia in successful SPK transplants has no effect on the subsequent course of diabetic retinopathy. ${ }^{8}{ }^{15-19}$ These studies have monitored the course of DR in successful SPK transplants recipients and compared them with less than ideal control groups which consisted of either failed SPK transplant recipients or kidney alone transplant recipients. Of particular concern in some studies, is that a small percentage of SPK transplant recipients have responded with a rapid deterioration in their retinopathy status. $^{8} 9$

In our own cohort of patients, if the retinopathy was stable for the 2 years pretransplant then $100 \%$ of eyes remained stable posttransplantation for a minimum mean follow up of 5 years. For those eyes that had unstable retinopathy in the 2 years before transplantation more than $90 \%$ stabilised following successful SPK transplant.

A major bias in this, and many other studies, is that the majority of eyes have advanced retinopathy and have received photocoagulation and/or vitrectomy before transplantation. Thus, we might expect a large proportion of cases to have stabilised through these interventions irrespective of any effect of the transplanted organs. However, in our cohort of successful SPK transplants recipients we have four cases (eight eyes) which had only mild background DR before transplantation (Table 1: patient Nos 1, 2, 3, and 4). All these eyes have remained stable throughout the period of the study and have not required any laser photocoagulation or vitrectomy.

We have not used the cohort of failed SPK transplant cases as a control group as the number of cases was too small to enable us to draw significant and reliable conclusions.

We have only a single case in our successful SPK transplant cohort that had progression of their retinopathy following transplantation. This progression occurred within the first 12 months following transplantation and subsequent to laser photocoagulation has remained stable. There have been several reports of accelerated progression of retinopathy after rapid induction of tight metabolic control in pancreatic transplant recipients, particularly after a prolonged period of inadequate control. ${ }^{8}$ A similar phenomenon has been recognised in some cases recruited to the DCCT. ${ }^{1}$ The mechanism responsible for this rapid deterioration is unclear, but may be related to a reduction in the hyperglycaemic enhanced rate of retinal blood flow and subse- quent retinal ischaemia, or to systemic hormonal changes such as growth hormone..$^{25-27}$

A further aspect of our study was to consider the incidence and nature of posttransplantation ocular complications that may occur. This is of particular relevance when we consider the lifetime, intensive immunosuppressive regimens these cases must endure. Forty one per cent of successful SPK transplant recipients have subsequently proceeded to cataract surgery. All these cases were receiving systemic steroids. Blankenship reported that $42 \%$ of eyes treated with argon laser PRP in the Diabetic Retinopathy Study ultimately required cataract surgery. ${ }^{28}$ However, this was after a longer follow up of 15 years compared with the mean follow up of 5.1 years of patients in our study.

A further three eyes developed poor IOP control, again all in patients receiving systemic steroids. These clinically significant consequences of steroid immunosuppression need to be considered in all cases. Although previous studies have attributed isolated cases of optic neuropathy and cytomegalovirus retinitis to the use of cyclosporin $\mathrm{A}$ and the other immunosuppressive agents we have no cases afflicted with these conditions. ${ }^{29}$

In summary, diabetic retinopathy in our cohort of successful SPK transplant recipients cases was generally stable post-transplantation with only one eye requiring further intervention. However, we recommend continued ophthalmic follow up of these cases as we do have documented progression. In our own study, and previous reported studies, the most critical time for progression of retinopathy may be that first 12 months of metabolic normalisation and thus we would recommend ophthalmic follow up, particularly in this first year.

What still needs to be elucidated is the effect on diabetic retinopathy when cases with less end organ disease are operated on at earlier stages as the knowledge and experience of pancreas transplantation evolves.

1 The Diabetes Control and Complications Trial Research Group. The effect of intensive treatment of diabetes on the development of long-term complications in insulindependent diabetes mellitus. N Engl f Med 1993;329:97786.

2 Kelly WD, Lillehei RC, Merkel FK, et al. Allotransplantation of the pancreas and duodenum along with the kidney in diabetic nephropathy. Surgery 1967;61:827-37.

3 International pancreas transplant registry. Newsletter 1998; 10:1-14.

4 Remuzzi G, Ruggenenti P, Mauer SM. Pancreas and kidney/pancreas transplants: experimental medicine or real improvement? Lancet 1994;343:27-31.

5 Calafiore R. Perspectives in pancreatic and islet cell transplantation for the therapy of IDDM. Diabetes Care 1997;20:889-96.

6 Sutherland DE. The case for pancreas transplantation. Diabet Metab 1996;22:132-8.

7 Larsen JL, Stratta RJ. Pancreas transplantation: a treatment option for insulin-dependent diabetes mellitus. Diabet Metab 1996;22:139-46.

8 Ramsay RC, Goetz FC, Sutherland DE, et al. Progression of diabetic retinopathy after pancreas transplantation for insulin-dependent diabetes mellitus. $N$ Engl $f \mathrm{Med}$ 1988;318:208-14

9 Zech JC, Trepsat D, Gain-Gueugnon M, et al. Ophthalmological follow-up of type 1 (insulin-dependent) diabetic patients after kidney and pancreas transplantation. Diabetologia 1991;34:S89-91.

10 Ulbig M, Kampik A, Thurau S, et al. Long-term follow-up of diabetic retinopathy for up to 71 months after combined renal and pancreatic transplantation. Graefes Arch Clin Exp Ophthalmol 1991;229:242-5. 
11 Black PD. Visual status of diabetic patients after pancreatic and other organ transplantation. Preliminary report. Trans and other organ transplantation. Pre

12 Brekke IB, Ganes T, Syrdalen P, et al. Combined renal and pancreatic transplantation: effects on advanced diabetic neuropathy and retinopathy. Life Support Syst 1985;3:680-4.

13 Konigsrainer A, Miller K, Steurer W, et al. Does pancrea transplantation influence the course of diabetic retinopathy? Diabetologia 1991;34:S86-8.

14 Zehr PS, Milde FK, Hart LK, et al. Pancreas transplantation: assessing secondary complications and life quality. Diabetologia 1991;34:S138-40.

15 Wang Q, Klein R, Moss SE, et al. The influence of combined kidney-pancreas transplantation on the progression of diabetic retinopathy. A case series. Ophthalmology 1994;101: 1071-6.

16 Petersen MR, Vine AK. Progression of diabetic retinopathy after pancreas transplantation. The University of Michigan ogy 1990;97:496-500.

17 Bandello F, Vigano C, Secchi A, et al. Effect of pancreas transplantation on diabetic retinopathy: a 20 -case report. Diabetologia 1991:34:S92-4.

18 Caldara R, Bandello F, Vigano C, et al. Influence of successful pancreaticorenal transplantation on diabetic retinopathy. Transplant Proc 1994;26:490.

19 Scheider A, Meyer-Schwickerath E, Nusser J, et al. Diabetic retinopathy and pancreas transplantation: a 3-year followup. Diabetologia 1991;34:S95-9.

20 Sells RA, Taylor JD, Brown MW, et al. Selection for low cardiovascular risk markedly improves patient and graft survival in pancreatic and renal transplant recipients. Transplant Proc 1995;27:308.
21 Kinkhabwala M, Wilkinson A, Danovitch G, et al. The role of whole organ pancreas transplantation in the treatment of type I diabetes. Am F Surg 1996;171:516-20.

22 Hathaway DK, Winsett RP, Milstead J, et al. Quality of life outcomes associated with variable posttransplant prednisone dosing regimens. F Transplant Coord 1996;6: 64-8.

23 Milde FK, Hart LK, Zehr PS. Pancreatic transplantation. Impact on the quality of life of diabetic renal transplant recipients. Diabetes Care 1995;18:93-5.

24 Schareck WD, Hopt UT, Geisler F, et al. Quality of life after combined pancreas-/kidney transplantation. Transplant Proc 1994;26:518-9.

25 Press M, Tamborlane WV, Sherwin RS. Importance of raised growth hormone levels in mediating the metabolic derangements of diabetes. $N$ Engl F Med 1984;310: $810-5$.

26 Rabin D, Bloomgarden ZT, Feman SS, et al. Development of diabetic complications despite the absence of growth hormone in a patient with post-pancreatectomy diabetes. New Engl f Med 1984;310:837-9.

27 Gerich JE. Role of growth hormone in diabetes mellitus. $N$ Engl f Med 1984;310:848-50.

28 Blankenship GW. Fifteen-year argon laser and xenon photocoagulation results of Bascom Palmer Eye Institute's patients participating in the diabetic retinopathy study. patients participating in the
Ophthalmology 1991;98:125-8.

29 Bandello F, Vigano C, Secchi A, et al. Diabetic retinopathy after successful kidney-pancreas allotransplantation: a survey of 18 patients. Graefes Arch Clin Exp Ophthalmol 1991; 229:315-8. 